\title{
Nanofiber as a novel vehicle for transdermal delivery of therapeutic agents: challenges and opportunities
}

\author{
Lalit Kumar $^{1,2^{*}} \mathbb{0}$, Shivani Verma ${ }^{3}$, Kajal Joshi ${ }^{2,4}$, Puneet Utreja ${ }^{5}$ and Sumit Sharma ${ }^{6}$
}

\begin{abstract}
Background: Transdermal delivery of drugs is a quite challenging task for pharmaceutical scientists. The transdermal route is preferred over the oral route due to various advantages like avoidance of the first-pass effect, non-invasiveness, and high patient compliance. Therefore, it is necessary to develop an effective carrier system that enables the effective passage of the drug through the dermal barrier.

Main body of abstract: Various novel drug delivery systems are used to enhance the permeation of a variety of drugs through the skin barrier. Researchers around the globe have explored nanofibers for the transdermal delivery of various therapeutic agents. Nanofibers are designed to have a high concentration of therapeutic agents in them promoting their flux through various skin layers. Polymeric nanofibers can be explored for the loading of both hydrophilic and lipophilic drugs. Biopolymer-based nanofibers have been also explored for transdermal delivery. They are capable of controlling the release of therapeutic agents for a prolonged time.
\end{abstract}

Short conclusion: The literature presented in this review paper provides significant proof that nanofibers will have an intense impact on the transdermal delivery of different bioactive molecules in the future.

\section{Graphic abstract:}

Keywords: Flux, Nanofibers, Permeation, Skin barrier, Transdermal

\section{Background}

Skin is the outermost lipidic barrier of the body with a thickness of 20-25 $\mu \mathrm{m}$ [1]. Besides the barrier function, it also helps in the absorption of various therapeutic and non-therapeutic molecules [2]. The presence of skin appendages like hair follicles can also be responsible for the passive absorption of drug molecules through the transdermal route (Fig. 1) [3]. Since drug molecules can directly enter into the systemic circulation after crossing this barrier, therefore, this route has attracted pharmaceutical scientists to perform research in the field of

\footnotetext{
*Correspondence: Ikpharma27@gmail.com

1 Department of Pharmaceutics, Himachal Institute of Pharmaceutical Education \& Research, Bela, National Highway 88, Nadaun, Himachal Pradesh 177033, India

Full list of author information is available at the end of the article
}

drug delivery for the last two decades [4]. The transdermal route is considered a better alternative to the oral route of drugs due to the prevention of dose fluctuations, first-pass hepatic metabolism, and increased bioavailability [5]. Moreover, the non-invasive nature and ease of application of dosage form through this route have helped to gain popularity among patients [6]. Numerous factors should be considered before developing transdermal delivery systems of drugs like skin barrier only allows penetration of hydrophobic drug molecules through it with molecular weight less than $500 \mathrm{kDa}$ (kilodaltons) [7]. The rate of influx of drugs is very slow through this barrier. However, the effective delivery of hydrophilic drugs through the skin is still a challenging task [8].

There are various nanocarrier systems like liposomes, niosomes, solid lipid nanoparticles, nanostructured 
lipid carriers, ethosomes, and polymeric nanoparticles which are explored for effective transdermal delivery of drugs [9]. However, polymeric micro or nanofibers have gained special attention for effective transdermal delivery of drugs for the last decade [10]. Various methods explored for the production of nanofibers are electrospinning, template synthesis, and phase separation [11]. However, electrospinning is the most widely used technique among all of them due to its cost-effectiveness and simplicity [12]. Nanofibers are generated in the form of the mat from electrospinning (Fig. 2) revealing various advantages like high surface area, nanopore size, and unique physicochemical properties [13]. These characteristic traits of nanofibers make them a suitable candidate for the delivery of drugs and genes [14]. Nanofibers may be an excellent choice for tissue engineering and dressing wounds due to their capability to produce a local effect [15]. There are various categories of drugs like anticancer, NSAIDs (Non-steroidal anti-inflammatory drugs), and antibiotics which are delivered through the transdermal route exploring nanofibrous mats [16]. This paper summarizes the utility of nanofibrous mats/scaffolds for transdermal delivery of various categories of bioactive molecules.

\section{Main text}

\section{Methods of production of nanofibers}

Nanofibers come under the category of nanostructured vehicles having a diameter of individual fiber below $100 \mathrm{~nm}$ [17]. Although developed fibers with a diameter in the range of 100-1000 $\mathrm{nm}$ are also designated as nanofibers and they are generally manufactured using a technique known as electrospinning [18]. Various

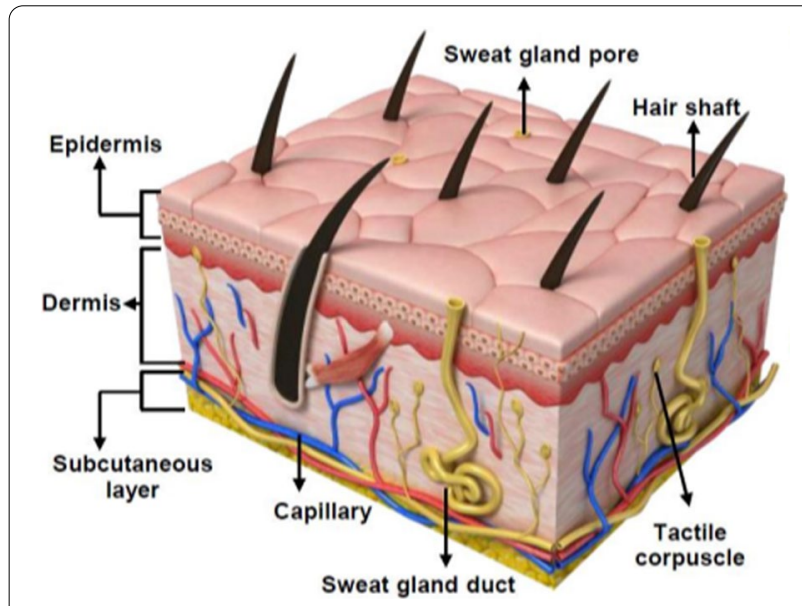

Fig. 1 Schematic illustration of human skin. (Adapted with permission from [3] copyright 2015 Lee et al.) methods explored for the production of nanofibers are shown in Fig. 3.

\section{Self-assembly method}

There is a spontaneous arrangement of atomic/molecular aggregates into structurally defined nanofibrous form in this method. This method leads to the production of nanofibers of a size range up to $100 \mathrm{~nm}$. This method requires a higher time to generate nanofibers, therefore, less commonly implemented. However, nanofibers manufactured through a self-assembly method can mimic natural materials like chitin (polysaccharide) very closely that has been explored in tissue engineering [19].

\section{Template synthesis method}

Template synthesis involves the use of nanoporous membranes that are available in the form of templates to extrude available fibers of different sizes into the nanoscale size range. The size of nanofibers produced lies in the range of $200-400 \mathrm{~nm}$ [20].

\section{Phase-separation method}

This method involves lyophilization of polymeric blend resulting in the formation of the nanofibrous mat. However, this method is very time-consuming and nanofibers obtained through this method are shorter in length with a size range of $50-500 \mathrm{~nm}$ [21].

\section{Melt-blown technology}

Melt blown method involves extrusion of polymer blend across a minute orifice followed by passage through heated air stream with a very high velocity. The size of nanofibers produced exploring this method is 150 $1000 \mathrm{~nm}[22]$.

\section{Electrospinning}

Electrospinning is the most widely used technique for nanofiber production. Fibers generated through the electrospinning method may lie in the nanometer to the micrometer size range. It is considered a cheap and scalable technique for the production of nanofibers [23]. Nanofibers are also produced by a modified electrospinning technique known as 'nanospider'. This technique generates nanofibers in the form of nonwovens with a diameter range of 50-300 $\mathrm{nm}$ [24]. Nanofibrous nonwovens are widely explored in various fields of biomedical engineering like wound dressing and tissue engineering, transdermal drug delivery, and enzyme immobilization [25]. Electrospinning involves the preparation of polymeric melt/solution initially followed by application of electric charge on it after its extrusion from nozzle/ 

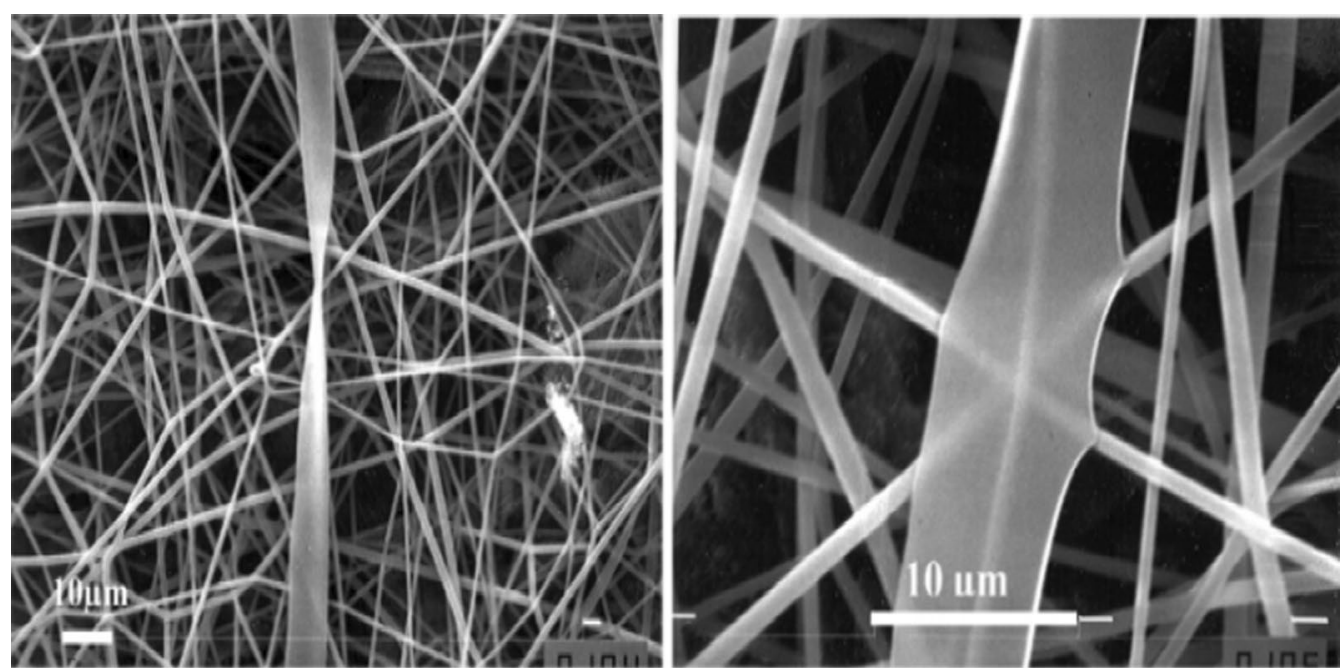

Fig. 2 Scanning electron micrographs showing flat ribbons formation during electrospinning of PET (polyethylene terephthalate) from a solution of $13 \mathrm{wt} . \%$ in 1:1 dichloromethane and trifluoroacetic acid. Left magnification $\times 1000$, right: an enlarged image with magnification $\times 3500$. (Adapted with permission from [13] copyright 2003 Frenot and Chronakis)

syringe/pipette [26]. Finally, the developed nanofibers are collected on the aluminum wall due to electrostatic attraction between polymer and wall (due to the presence of opposite charge on both) (Fig. 4) [27].

\section{Methodologies of drug loading in nanofibers}

Various methodologies of loading drugs into nanofibers are discussed below:

\section{Co-electrospinning}

This approach involves the simple mixing of the polymeric solution with the drug before the initiation of electrospinning. A homogeneous solution of drug and polymer in a single solvent is further subjected to electrospinning and this type of electrospinning is called co-electrospinning [28]. This technique shows high loading efficacy and homogeneous drug distribution within the nanofibrous network [29]. The loading efficiency of nanofibers produced through this method depends on the physicochemical properties of the polymer used followed by the interaction of polymers with drug molecules [30]. The morphology of nanofibers and the distribution of drug molecules within them may affect their release kinetics [31]. Various natural polymers like gelatin, collagen, and chitosan are used to develop nanofibers loaded with hydrophilic drugs due to their complete dissolution in the aqueous phase [32]. Nanofibers produced through this method collapse during the cross-linking process creating problems in the electrospinning process. This can be due to the reduced viscosity of the solution and this problem can be overcome by using synthetic

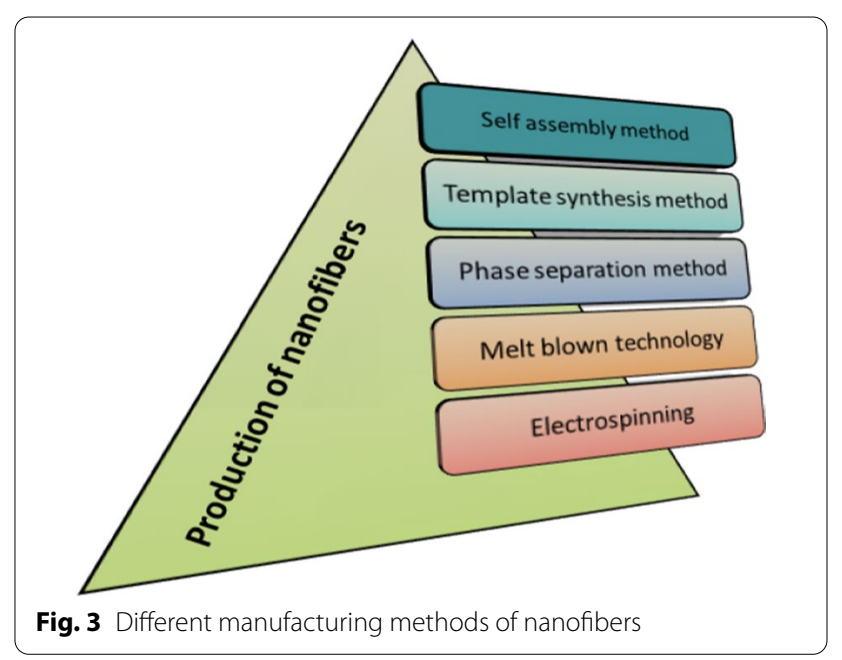

hydrophilic polymers like PEO (Polyethylene oxide) additionally. Nanofibers developed through this method can lead to a burst release effect also [33].

\section{Immobilization of drug molecules on the surface of nanofibers}

Various therapeutic drug molecules can be loaded in nanofibers following the surface immobilization method through various physical and chemical mechanisms. Various forces involved in physical immobilization are electrostatic forces, hydrogen bonding, or weak van der Waals forces [34]. Chemical immobilization involves the direct attachment of drug molecules over the nanofiber 
surface through functionalization with various groups like thiol, carboxyl, hydroxyl, and amine [35]. The surface immobilization method does not cause denaturation of drug molecules as observed in the case of the co-electrospinning method due to excessive use of organic solvents and high voltage [36]. The amount of drug to be immobilized on the surface of nanofibers can also be controlled by using this technique through optimization of drug feeding ratio. This approach is also capable of blocking initial burst release from nanofibers promoting slow release kinetics [37].

\section{Co-axial electrospinning}

Immiscibility between drug molecules and the polymer may create problems in the co-electrospinning process. Therefore, for loading different kinds of drugs having a difference in solubilities in polymers a new technique named 'co-axial electrospinning' is used [38]. Co-axial electrospinning is done with the help of a spinneret needle having one inner and one outer nozzle organized concentrically. There is the presence of two different chambers for the handling of sheath solution and core solution. The final solution is ejected from the co-axial cone (Fig. 5) [39]. This technique enables the electrospinning of two non-miscible polymers having therapeutic agents in core and sheath as well [40]. Electrospinning through this technique results in high drug loading capacity and prevention of initial burst release due to the presence of a stagnant sheath [41]. Generally, hydrophilic polymers and therapeutic agents like proteins are enclosed in the core portion while hydrophilic elements remain in the sheath. Co-axial electrospinning requires controlling a large number of factors like the feeding speed of polymeric solution, voltage application, and concentration of therapeutic agents for the production of nanofibers with proper core and sheath structure [42].

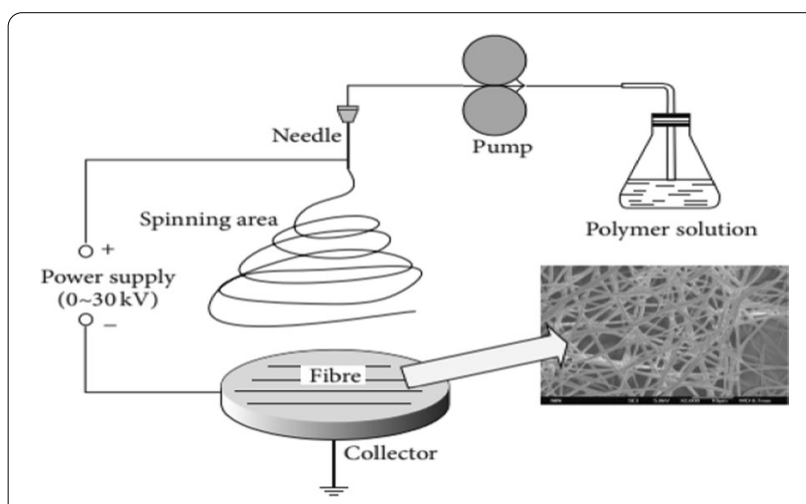

Fig. 4 Overview of electrospinning technique. (Adapted with permission from [27] copyright 2015 Wang et al.)

\section{Emulsion electrospinning}

Emulsion electrospinning involves the emulsification of an aqueous solution of a therapeutic agent or protein with a lipophilic polymeric solution [43]. Furthermore, the drug-loaded phase is disseminated in the nanofibers at the termination of electrospinning (Fig. 6). While using this method, the distribution of drug molecules within the nanofiber is totally dependant on the ratio of hydrophilic to the lipophilic solution used [44].

Therapeutic agents and polymers can be dissolved in suitable solvents using this technique. This method involves minimal exposure to the therapeutic agent with an organic solvent [45]. The emulsion electrospinning method allows the use of a variety of hydrophilic drugs and lipophilic polymer combinations [46]. The existence of interfacial tension and strong shearing forces between two phases of the emulsion can degrade the proteinaceous drug molecules due to their high sensitivity [47]. The use of ultrasonication methodology in this electrospinning technique can damage the drug molecules reducing the efficacy of nanofiber produced [48].

\section{Applications of nanofibers in transdermal delivery of various therapeutic agents}

Various categories of drugs that are delivered through a transdermal route using nanofibers are discussed below:

\section{Antibiotics or antimicrobial drugs}

Cutaneous wounds infection may be responsible for increased healing duration, a longer period of hospitalization, and death of the patients many times [14]. Skin infections can be effectively treated by using antibiotics/antimicrobial drugs locally. Pharmaceutical scientists have investigated various antibiotics/antimicrobial drugs impregnated into nanofibers for the treatment of cutaneous wounds [16]. Kataria et al. [49] investigated ciprofloxacin-loaded polyvinyl alcohol and sodium alginate-based nanofibers for localized delivery and to treat the wound in rabbits. Ciprofloxacin-loaded nanofibers showed drug release in-vitro following Higuchi and Korsmeyer-Peppas model. The wound healing capacity of nanofibers was determined using hydroxyproline assay in wounds. Ciprofloxacin-loaded nanofibers showed the highest amount of hydroxyproline $(8.39 / 100 \mathrm{mg}$ of wound bed) in the animal wound after twenty days compared to the marketed formulation of ciprofloxacin (7.91/100 mg of wound bed) indicating their high effectiveness [49]. Furthermore, nanofibers composed of polymers poly(vinyl alcohol) and lysine and impregnated with ibuprofen (an anti-inflammatory agent) and lavender oil (anti-bacterial agent) were 

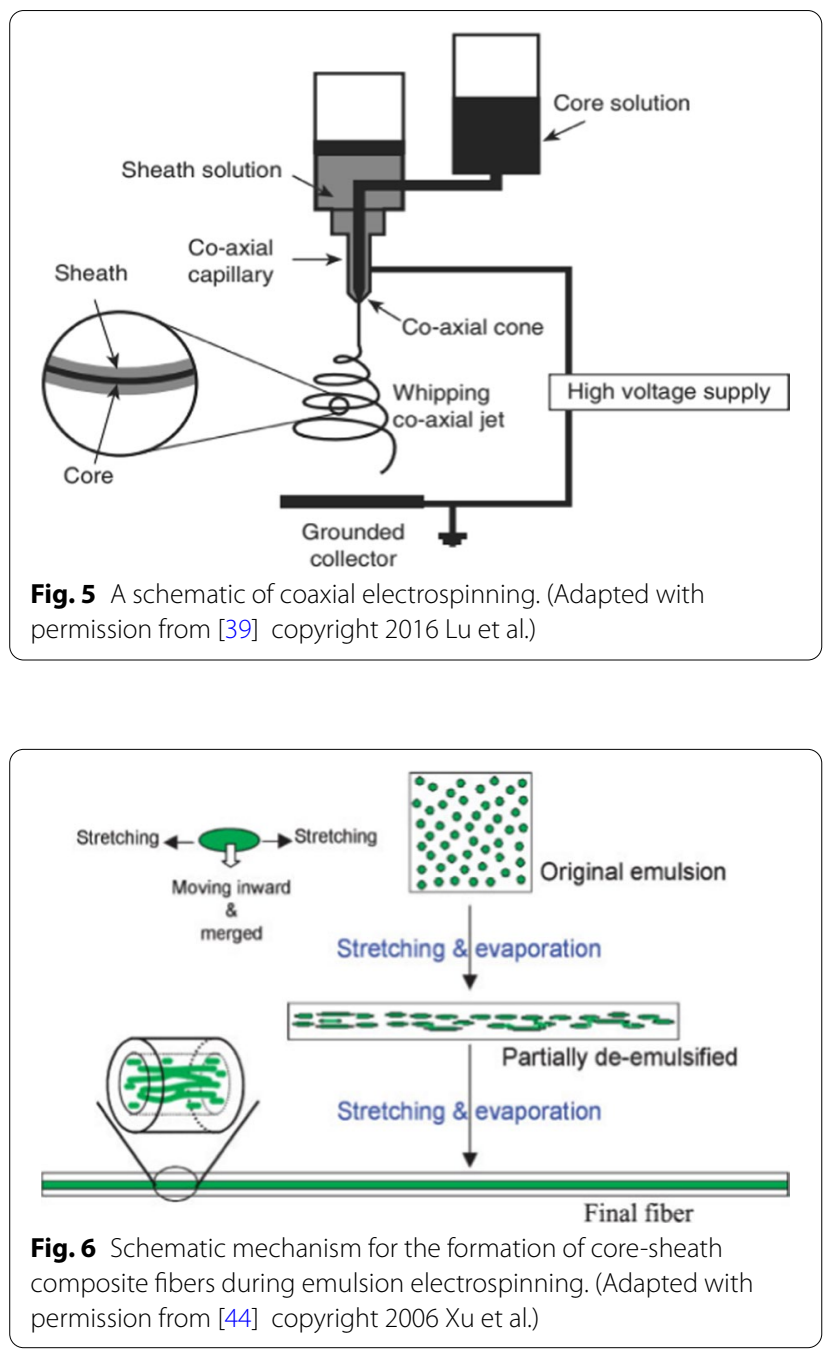

investigated by Sequeira et al. [50] for the acceleration of the wound healing process. Ibuprofen was loaded using the co-electrospinning technique while lavender oil was loaded using the surface adsorption technique in nanofibers. Nanofibers loaded with ibuprofen displayed a reduction in the time scale of the wound healing inflammatory phase. However, lavender oil-loaded nanofibers showed a very high in-vitro antibacterial efficacy against $S$. aureus and $P$. aeruginosa compared to nanofibers loaded with ibuprofen without affecting dermal fibroblasts [50] (Fig. 7).

Later on, Iqbal et al. [51] determined the efficacy of chitosan/poly(vinyl alcohol) nanofibers loaded with cefadroxil monohydrate against resistant gram-positive bacteria S. aureus responsible for chronic skin fungal infection. Nanofibers with 30:70 of chitosan/ poly(vinyl alcohol) were considered as optimized and these developed nanofibers showed high in-vitro antimicrobial activity against resistant S. aureus followed by low toxicity towards epidermal keratinocytes as depicted in MTT assay. They were considered a better alternative for the treatment of chronic skin fungal infections [51]. Table 1 gives a brief overview of nanofibers for transdermal delivery of various antimicrobial/antibiotic drugs.

\section{Antifungal drugs}

Polymeric electrospun nanofibers are also explored for transdermal delivery of various antifungal drugs. Harini et al. [61] investigated the antifungal potential of polycaprolactone (PCL)/egg lecithin-based nanofibers impregnated with terbinafine hydrochloride to treat skin fungal infections. Developed nanofibers with diameter $127.7 \pm 43.7 \mathrm{~nm}$ were found non-cytotoxic towards human dermal fibroblasts as revealed through confocal microscopy and they also showed excellent in-vitro antifungal activity against different fungal strains like Epidermophyton and Trichophyton mentagrophytes responsible for topical fungal infections [61]. Furthermore, Paskiabi et al. [62] formulated nanofibers loaded with terbinafine hydrochloride (TFH) using polymers polycaprolactone (PCL) and gelatin $(50: 50 \mathrm{w} / \mathrm{w})$ using glutaraldehyde (GTA) as a cross-linking agent. TBHloaded nanofibers showed non-cytotoxic behavior as evaluated in L929 cells. Cross-linked nanofibers loaded with TBH showed $100 \%$ drug loading followed by a high in-vitro antifungal activity against $T$. mentagrophytes and $A$. fumigates and less effective against $C$. albicans (Fig. 8) [62]. Later on, voriconazole impregnated polyvinyl alcohol (PVA)/sodium alginate nanofibers were formulated by Esentürk et al. [63] and further cross-linked with glutaraldehyde (GTA) for effective delivery through the transdermal route. Cross-linked polymer composite nanofibers loaded with voriconazole showed high drug loading (96.45 $\pm 5.91 \%)$ followed by low in-vitro cytotoxicity against mouse fibroblast cells. Voriconazole impregnated polyvinyl alcohol (PVA)/sodium alginate nanofibers showed high in-vitro antifungal activity against $C$. albicans and deeper penetration of drug in the lower skin layer compared to the solution of voriconazole in propylene glycol [63]. Esenturk et al. [64] explored polyurethane/polyvinylpyrrolidone/silk nanofibrous mats loaded with sertaconazole nitrate for transdermal treatment of fungal infection caused by C. albicans. Developed nanofibers showed approximately $89.97 \pm 1.40 \%$ loading of sertaconazole nitrate and sustained its release for up to $168 \mathrm{~h}$ in-vitro. Sertaconazole nitrate loaded in nanofibers showed fungistatic action towards $C$. albicans and excellent in-vitro biocompatibility for mouse fibroblast cell lines as revealed in the CCK-8 assay [64].

Later on, Azarbayjani et al. [65] developed nanofibers of Polyvinyl alcohol and chitosan for transdermal 
delivery of hydroquinone and investigated the effect of chitosan on their efficacy. Optimized hydroquinoneloaded nanofibers showed a diameter of $537.24 \pm 52.5 \mathrm{~nm}$ and drug loading of $4.4 \%$. Increasing the concentration of chitosan up to $2 \%$ in the formulation did not cause any significant changes in nanofiber diameter, loading percentage, and in-vitro antifungal activity against Candida albicans, however, it was able to increase the in-vitro release of hydroquinone at $32{ }^{\circ} \mathrm{C}$ compared to $25^{\circ} \mathrm{C}$ [65].

\section{Anti-inflammatory drugs}

Electrospun nanofibers have also been investigated by pharmaceutical scientists for the transdermal delivery of many anti-inflammatory drugs. Shi et al. [66] investigated Cellulose acetate/poly(vinyl pyrrolidone) based nanofibers impregnated with ibuprofen for transdermal delivery. Optimized nanofibers showed a diameter of $167 \pm 88 \mathrm{~nm}$ and X-Ray Diffraction analysis of nanofibers revealed uniform distribution of ibuprofen in the nanofibrous network in amorphous form. Developed nanofibers showed better in-vitro skin permeation of the drug followed by increased water vapor permeability compared to the conventional transdermal patch of the same drug indicating their high thermodynamic stability [66]. Furthermore, rosmarinic acid (RosA) loaded cellulose acetate (CA) nanofibers were evaluated by Vatankhah [67] for in-vitro anti-inflammatory activity (determination through protein denaturation assay), cytotoxicity, and antioxidant effect. Nanofibers formulated using 10\% rosmarinic acid were considered as optimized and they showed diameter $331 \pm 85 \mathrm{~nm}$ and drug loading (\%) $84 \pm 4 \%$. These nanofibers were capable of extending the release of rosmarinic acid up to $64 \mathrm{~h}$ through the Fickian diffusion mechanism and higher in-vitro anti-inflammatory activity compared to the ibuprofen solution. A promising
A

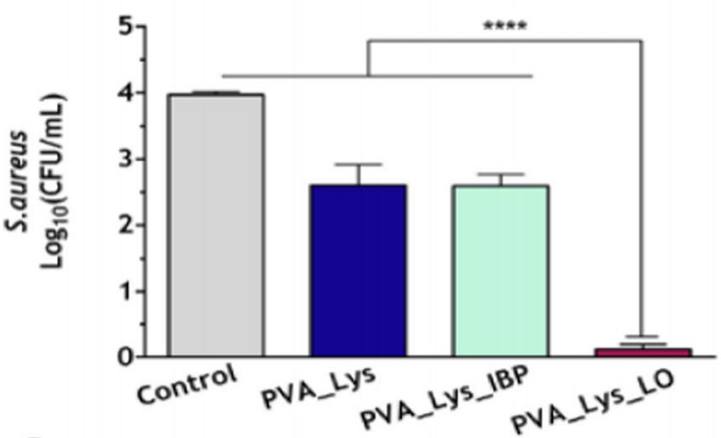

C
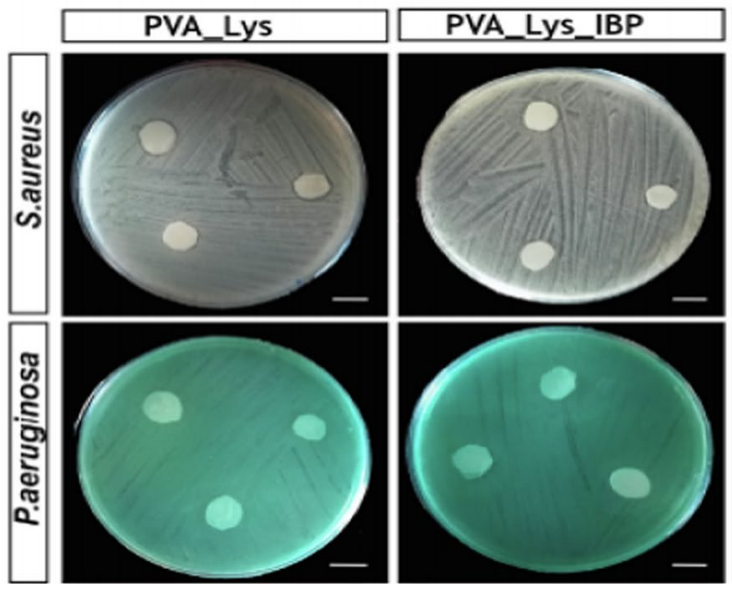

B

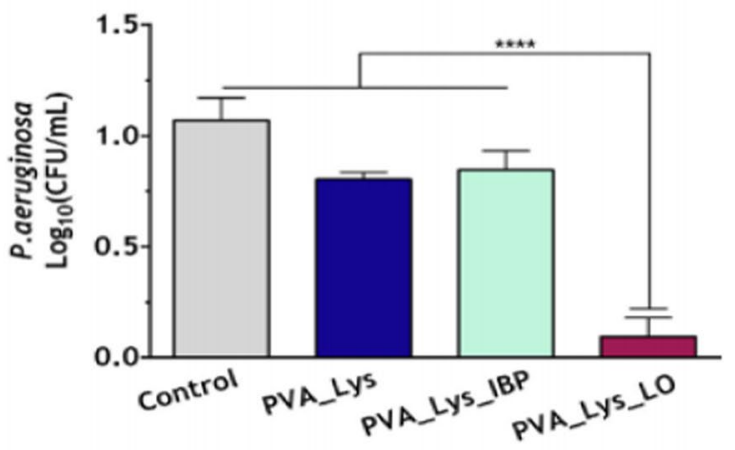

Fig. 7 Evaluation of the produced PVA_Lys electrospun membranes' antibacterial properties. Determination of the CFU/mL of S. aureus (A) and P. aeruginosa (B), when seeded in contact with the membranes. Macroscopic images and analysis of the inhibitory halos against $\mathrm{S}$. aureus and P. aeruginosa $(\mathbf{C})$. Data are presented as the mean \pm standard deviation, $n=5,{ }^{* *} p<0.001$, ${ }^{* * *} p<0.0001$. PVA_Lys blank poly(vinyl alcohol) and lysine nanofibers, PVA_Lys_IBP Ibuprofen loaded nanofibers, PVA_Lys_LO Lavender oil loaded nanofibers). (Adapted with permission from [50] copyright 2019 Sequeira et al.) 
Kumar et al. Futur J Pharm Sci $\quad$ (2021) 7:175

Page 7 of 17

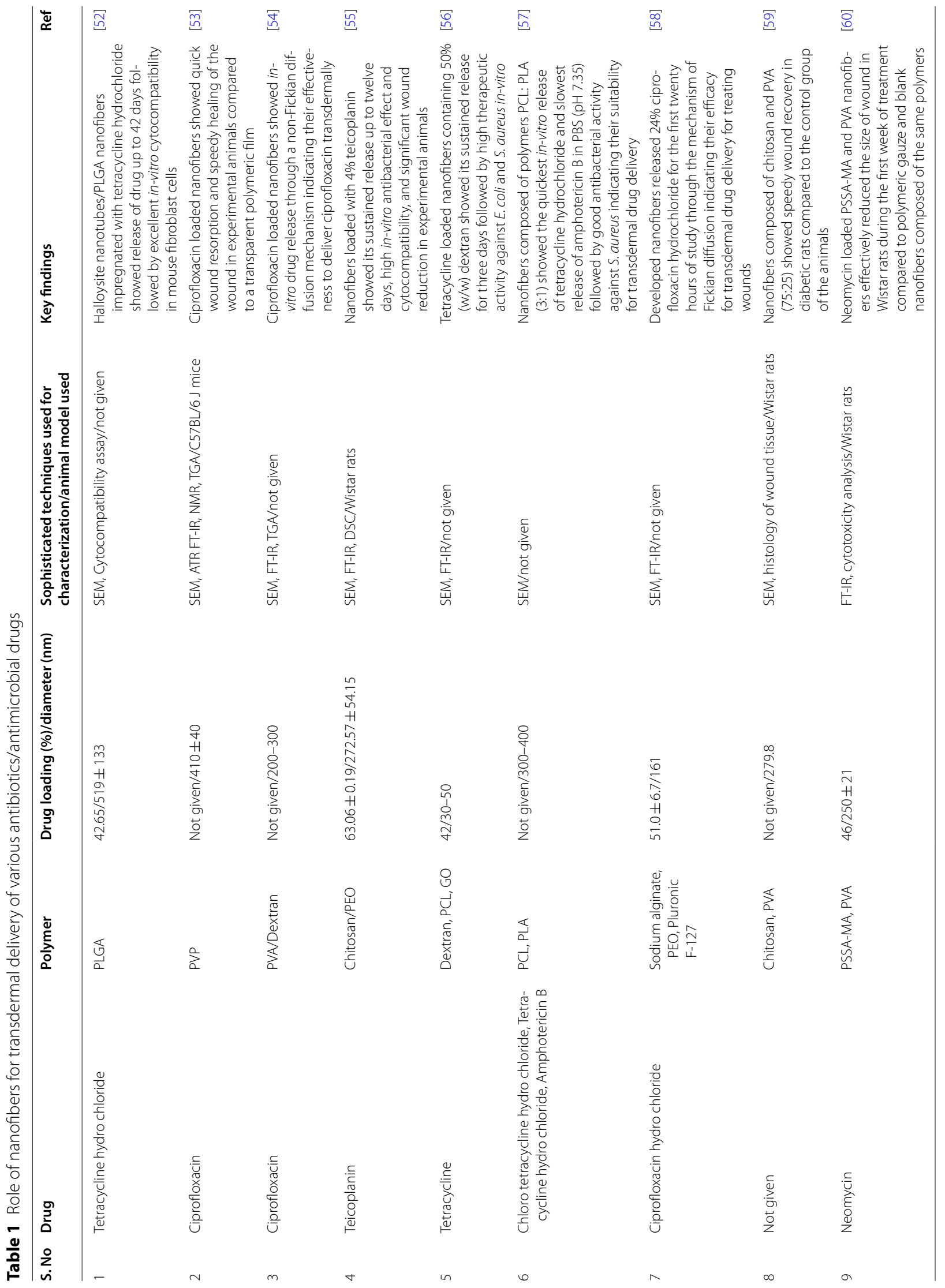




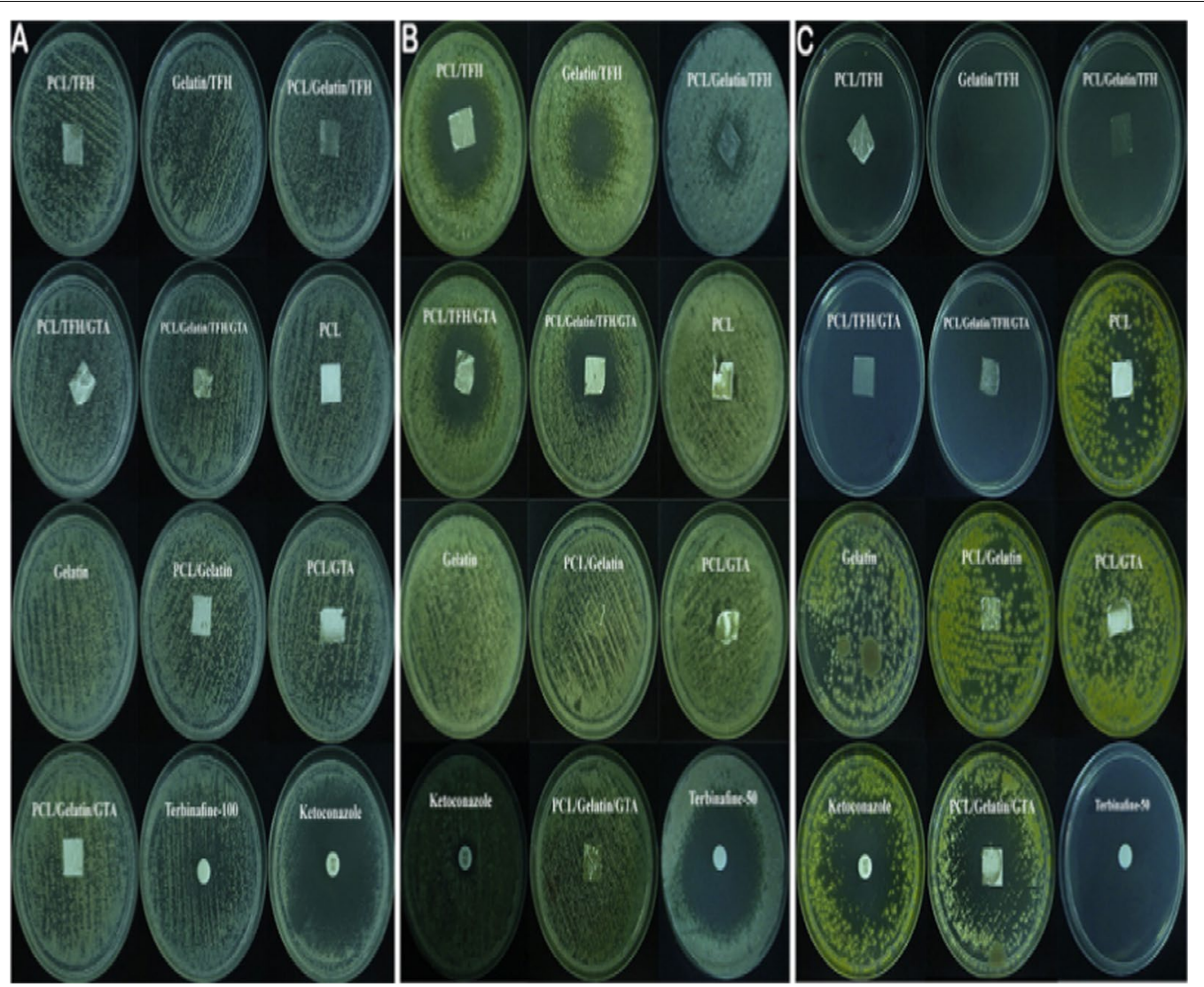

Fig. 8 Antifungal effects of nanofibers and antifungal disks on C. albicans after $48 \mathrm{~h}$ (A), on A. fumigatus after $72 \mathrm{~h}$ (B), and on T. mentagrophytes at $144 \mathrm{~h}$ of treatment (C). PCL/TFH terbinafine hydrochloride loaded polycaprolactone nanofibers; Gelatin/TFH terbinafine hydrochloride loaded gelatin nanofibers; PCL/Gelatin/TFH terbinafine hydrochloride loaded polycaprolactone/gelatine nanofibers; PCL/Gelatin/TFH/GTA terbinafine hydrochloride loaded polycaprolactone/gelatine/glutaraldehyde cross-linked nanofibers. (Adapted with permission from [62] copyright 2017 Paskiabi et al.)

in-vitro antioxidant effect was observed for nanofibers

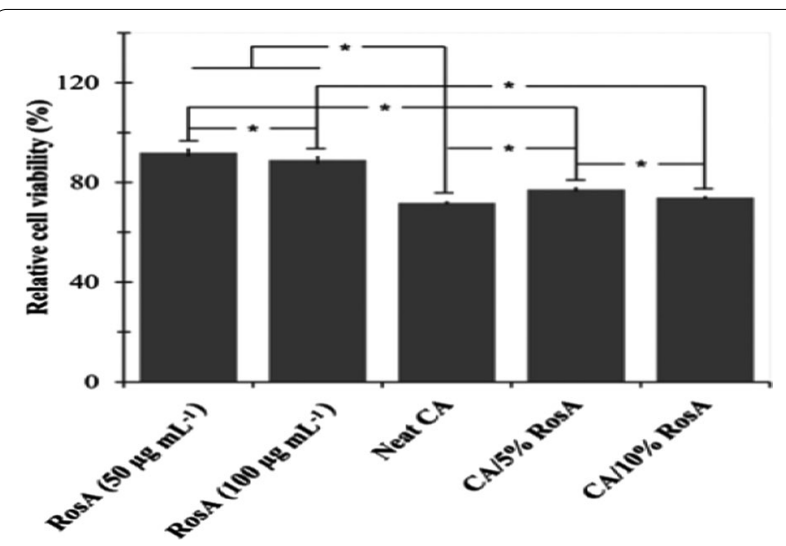

Fig. 9 Relative cell viability of epithelial cells cultured with RosA containing media and extraction media from neat and RosA loaded CA nanofibers (The relative cell viability of the control was defined as 100\%). * indicates significant differences. (Adapted with permission from [67] copyright 2018 Vatankhah) followed by very low cytotoxicity in epithelial cells (Fig. 9) [67].

Later on, an evaluation of poly(vinyl alcohol) based nanofibers loaded with diclofenac enclosed in zein nanoparticles was carried out by Ghalei et al. [68]. Developed nanofibers showed a diameter of $324.42 \pm 72.80 \mathrm{~nm}$ and good tensile properties for topical application. Nanofibers containing diclofenac loaded inside zein nanoparticles were considered best for wound healing due to their better in-vitro attachment in fibroblasts followed by the promotion of their proliferation [68]. The utility of nanofibers for transdermal delivery of various antiinflammatory drugs is given below in Table 2 .

\section{Anticancer drugs}

The local effect of anticancer drugs in the skin can be improved by loading them into a nanofibrous mat. Rengifo et al. [74] developed pyrazoline H3TM04 loaded nanoparticles and further impregnated them into nanofibers composed of polyethylene oxide-chitosan for 


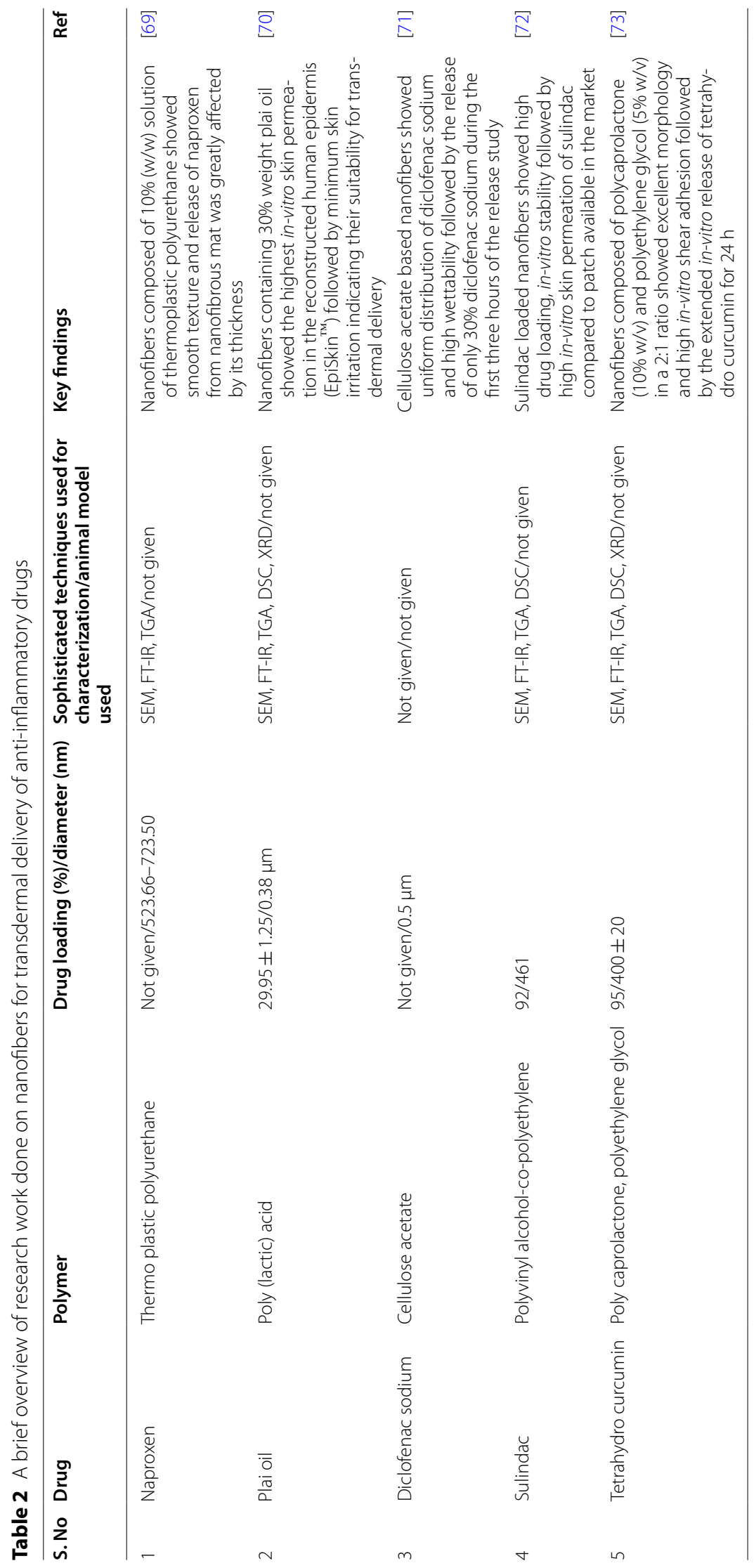




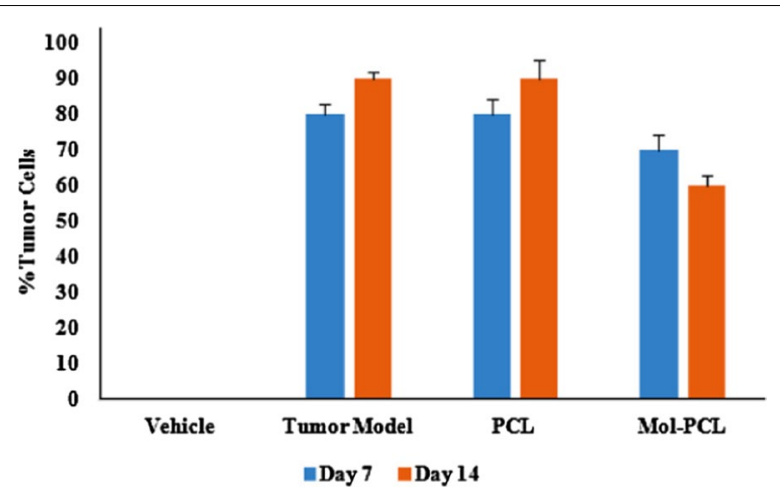

Fig. 10 Percentage of tumor cells in PCL and Mol-PCL treated zebra fishes on Day 7 and Day 14. PCL Blank polycaprolactone nanofibers; Mol-PCL polycaprolactone nanofibers loaded with molybdenum oxide nanoparticles. (Adapted with permission from [75] copyright 2018 Janani et al.)

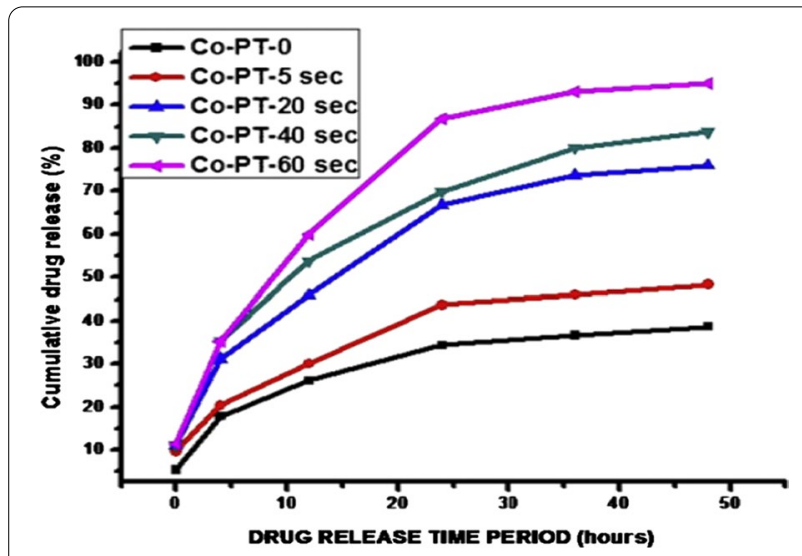

Fig. 11 Cumulative drug release measurements using UV spectrophotometer showing $35-95 \%$ release of vitamin $B_{12}$ with plasma treatment. (Adapted with permission from [81] copyright 2018 Madhaiyan et al.)

the treatment of skin cancer. Optimized nanoparticles loaded nanofibers showed a diameter of $197.8 \pm 4.1 \mathrm{~nm}$ and uniform distribution of nanoparticles throughout the nanofiber matrix followed by the extended-release of pyrazoline H3TM04 up to $120 \mathrm{~h}$. Developed nanofibers also enhanced in-vitro transport pyrazoline H3TM04 across the epidermal skin layer followed by excellent invitro cytotoxicity against B16F10 melanoma cells [74]. Furthermore, molybdenum oxide-loaded nanoparticles were prepared by Janani et al. [75] and impregnated into polycaprolactone (PCL) nanofibers for evaluation of their skin anticancer potential in zebrafish. Nanofibrous mat loaded with molybdenum oxide nanoparticles showed an average diameter of $200 \mathrm{~nm}$ and a significant reduction in in-vitro cell viability (>50\%) in A431 cells through mitochondrial dependant apoptosis. Nanofibers loaded with molybdenum oxide nanoparticles showed reduced skin cancer progression in zebrafish by more than $30 \%$ within two weeks (Fig. 10) [75].

Table 3 discloses the role of polymeric nanofibers in the transdermal delivery of various antineoplastic drugs.

\section{Other categories of drugs}

There are other categories of drugs other than those discussed above which can be delivered through the transdermal route exploring nanofibers for producing the evident pharmacological effect. Madhaiyan et al. [81] investigated polycaprolactone polymer-based nanofibers loaded with Vitamin $B_{12}$ for effective delivery through the transdermal route. Vitamin $B_{12}$ loaded nanofibers showed an average diameter of $1.226 \pm 0.108 \mu \mathrm{m}$ and $89 \%$ drug loading capacity followed by high mechanical strength and excellent surface wettability. Surface treatment of Vitamin $B_{12}$ loaded nanofibers with plasma greatly affected in-vitro release ate of Vitamin $\mathrm{B}_{12}$ from nanofibers. Nanofibers treated with plasma for $60 \mathrm{~s}$ showed the highest release of Vitamin $B_{12}$ within 50 h (Fig. 11). This could be due to the increased hydrophilicity of the nanofiber membrane after treatment with plasma [81]. Furthermore, hydrocortisone-loaded polyacrylonitrilebased nanofibers were formulated by Hemati Azandaryani et al. [82] and were investigated for topical treatment of psoriasis by varying amounts of surfactant Tween 80 in nanofiber composition. Nanofibers produced using polyacrylonitrile polymer along with $5 \%$ Tween 80 surfactant showed the lowest diameter $(160.11 \pm 30.11 \mathrm{~nm})$ and maximum tensile strength (15.35 MPa) followed by the highest in-vitro drug release for $12 \mathrm{~h}$ and minimum cytotoxic effect against HUVEC cell lines indicating their efficacy in transdermal drug delivery for the treatment of psoriasis [82].

The role of polymeric nanofibers in transdermal drug delivery of various therapeutic agents is given in Table 4 .

\section{Biopolymer based nanofibers in transdermal delivery}

Biopolymers are polymeric materials that are manufactured from natural provenance. Biopolymers are chemically produced from biological materials or their complete biosynthesis can be done by living organisms [90]. Various examples of biopolymers are cellulose, chitosan, hemicellulose, silk, and lignin. These biopolymers may be biocompatible and biodegradable promoting their use in drug delivery [91]. Nanomaterials that are derived usually derived from cellulose are called nanocellulose materials. These materials can be classified into three categories namely nanofibrillated cellulose, bacterial nanocellulose, and nanocrystalline cellulose 


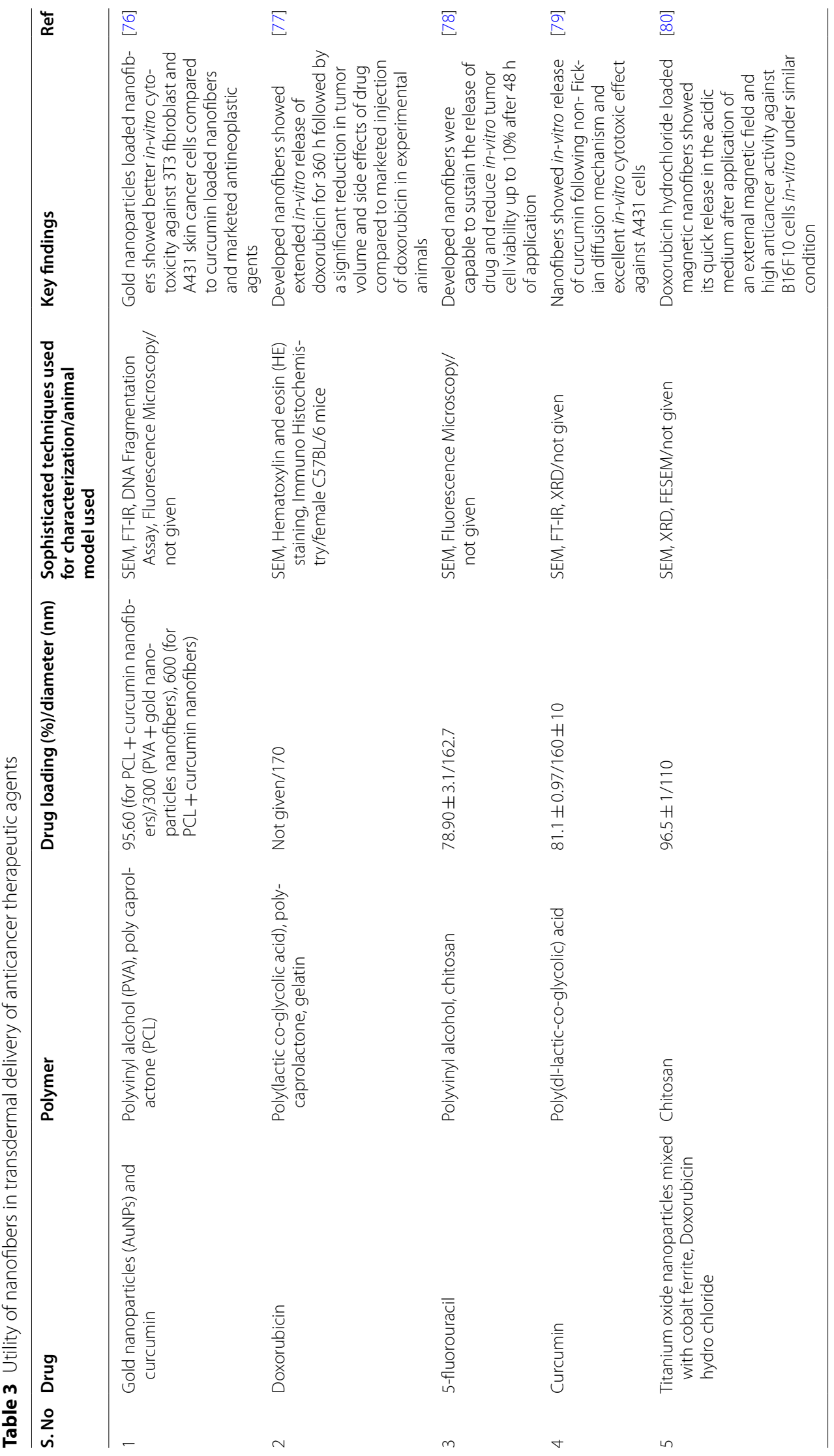




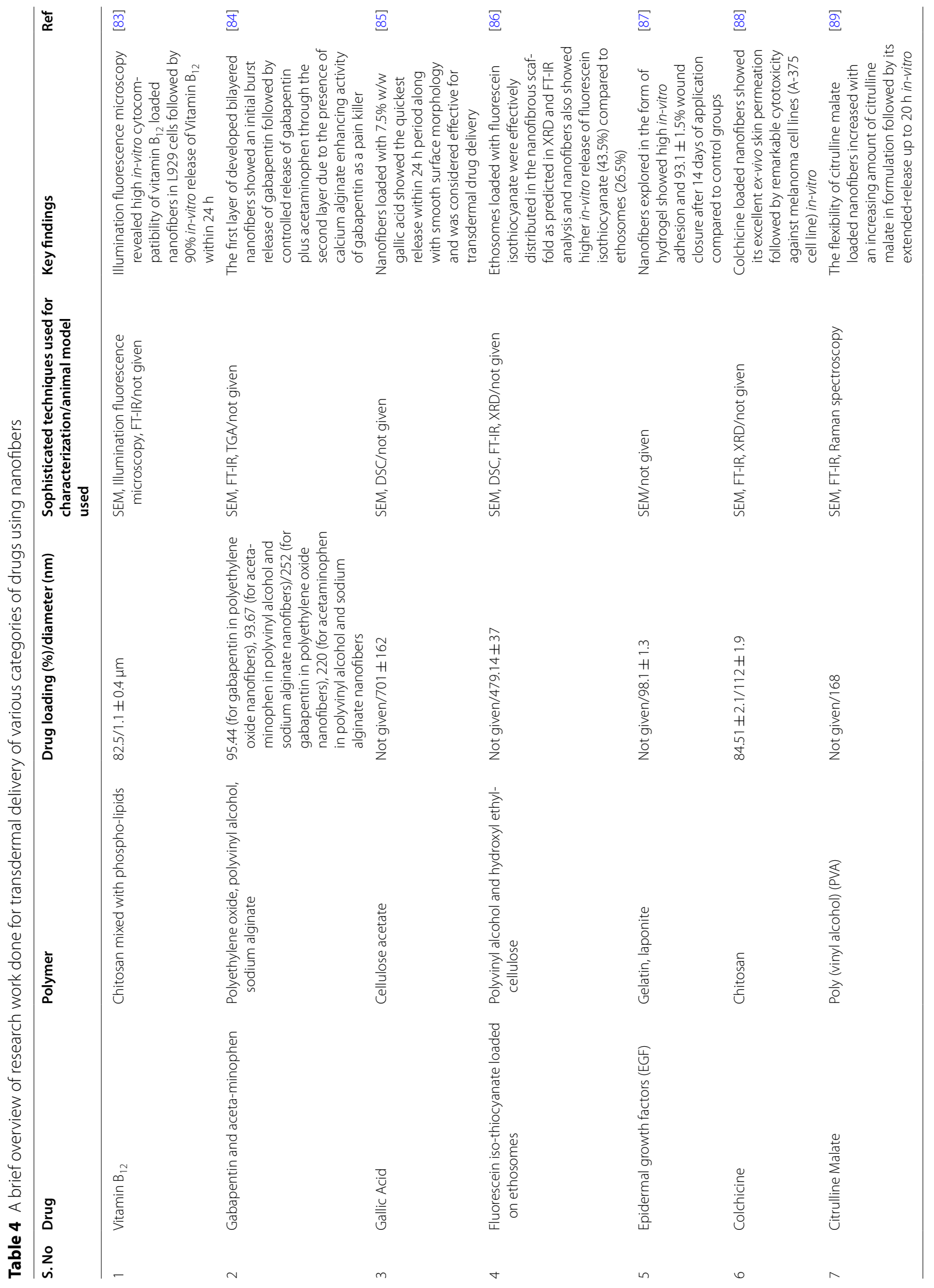




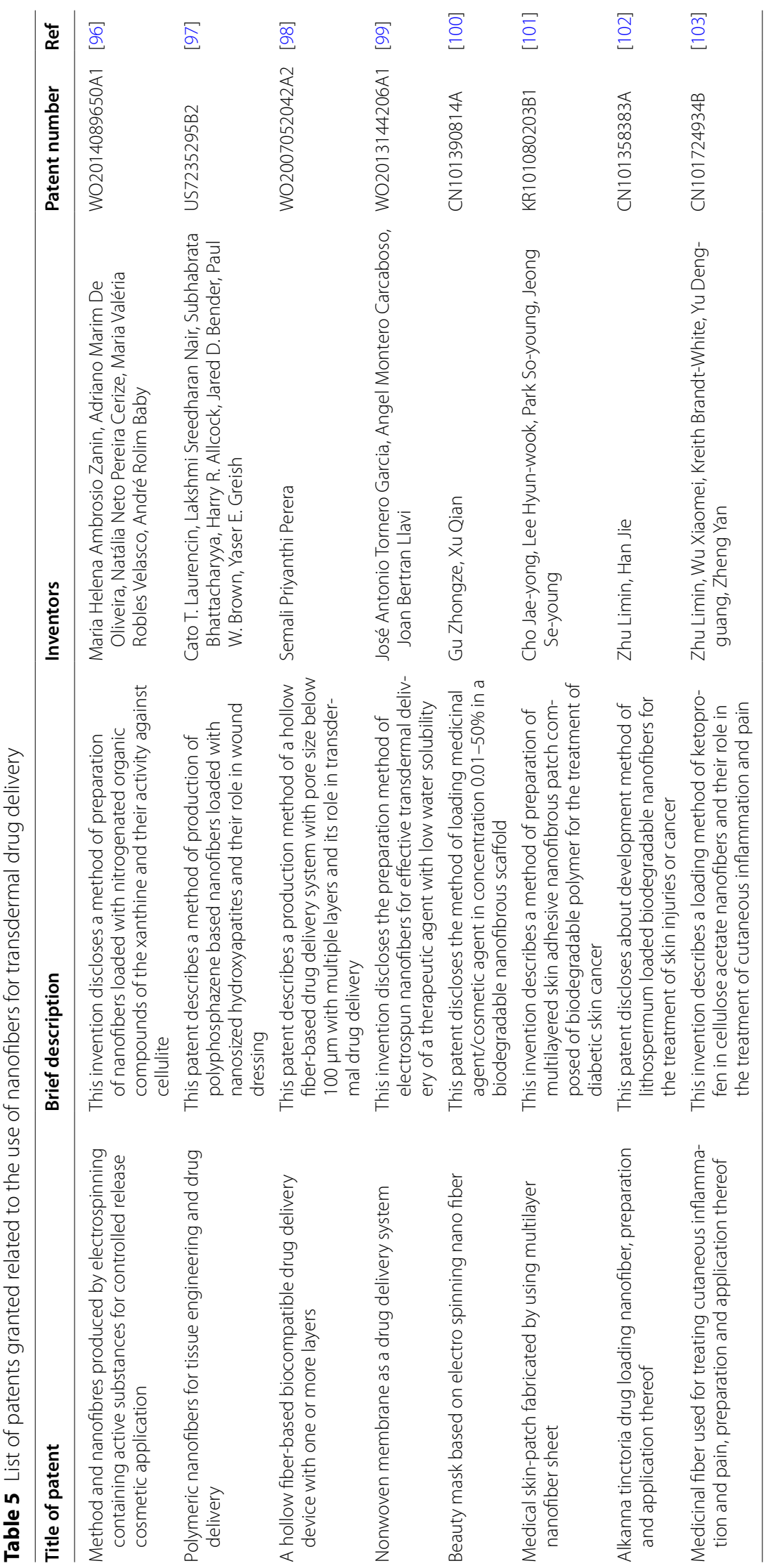


[92]. nanocellulose based materials show elevated surface area, ease of chemical modification, and a higher value of specific strength. Hence, nanocellulose can be explored as a good candidate for various biomedical utilities [93]. El-Wakil et al. [94] investigated the wound healing potential of coffee extract impregnated into bacterial cellulose (produced from kombucha tea fungus) biocomposites. Biocomposites composed of minimum coffee extract and cellulose amount disclosed maximum tensile strength $(3.35 \mathrm{MPa})$ and transmission of water vapors (3184.94 $\pm 198.07 \mathrm{~g} / \mathrm{m}^{2} /$ day) followed by least release of polyphenols in-vitro in PBS (pH 7.4) considered suitable for wound healing [94]. Furthermore, Shan et al. [95] developed cellulose nanocrystal incorporated calcium cross-linked sodium alginate/gelatin nanofibers for efficient wound healing. Developed nanofibers showed in-vitro non-toxicity against mouse embryonic fibroblast and improved cell adhesion. The cellulose nanocrystal incorporated calcium cross-linked sodium alginate/gelatin nanofibers showed excellent wound healing in Sprague Dawley rats through a re-epithelialization mechanism compared to the control group [95].

\section{Description of patents related to the use of nanofibers for transdermal delivery of various therapeutic agents}

A detailed literature investigation revealed the excellent therapeutic potential of nanofibers to treat various abnormal conditions of the skin. These nanofibrous scaffolds can be explored as a better alternative to conventional drug delivery systems for the transdermal treatment of various skin disorders. Hence, pharmaceutical researchers are filing patents regarding the use of nanofibers for transdermal drug delivery of various therapeutic agents. Table 5 discloses the list of patents granted regarding this context.

\section{Limitations and challenges in the exploration of nanofibers for transdermal drug delivery}

Polymeric nanofibers have shown promising potential in transdermal drug delivery, however, many significant challenges must be taken into consideration. All the research investigations available in the literature describe either in-vitro or in-vivo (in different animal models) efficacy of transdermal nanofibers. However, the clinical efficacy determination of nanofibers explored through the transdermal route is still a challenge. Clinical evaluation of nanofibers will be exorbitant and laborious. It will require high speculation by the industries or government funding agencies of the countries. The second major concern will be regarding the scale-up of transdermal nanofibers. Nanofibers are effectively produced through the electrospinning process following a low flow rate of polymeric solution, making the production process more time-consuming. Nanofibers production is also affected by humidity, hence it might be a challenging factor for bulk processing and scale-up of nanofibers. Furthermore, the production of transdermal nanofibers with GMP (Good manufacturing practices) standards will be required. The development of standard and universally accepted electrospinning protocol will govern their quick entrance into the pharmaceutical market.

\section{Conclusions}

Nanofibers have been explored for transdermal drug delivery due to their various merits like high drug loading, surface-to-volume ratio, and similarity with the extracellular matrix. Successful production of the nanofibrous mat is dependent on appropriate polymers and solvent selection for electrospinning. A nanofiber suitable for transdermal drug delivery can be produced using multiple polymer blends for electrospinning. Polymeric nanofibrous mat loaded with a therapeutic agent has the caliber to control/prolong its release transdermally. Transdermal nanofibers have shown their therapeutic potential in various preclinical investigations carried out by various pharmaceutical scientists. However, their entrance into the pharmaceutical market will be governed by developing effective scale-up technologies and detailed clinical evaluation.

\section{Abbreviations}

FT-IR: Fourier transform infrared spectrometer; SEM: Scanning electron microscopy; XRD: X-ray diffraction analysis; DSC: Differential scanning calorimetry; TGA: Thermogravimetric analysis; FESEM: Field emission scanning electron microscopy; PLGA: Poly(lactic-co-glycolic acid); PVP: Polyvinylpyrrolidone; ATR FT-IR: Attenuated total reflectance coupled with Fourier Transform Infrared spectrometer; NMR: Nuclear magnetic resonance spectroscopy; PVA: Poly (vinyl alcohol); PEO: Polyethylene oxide; PCL: Polycaprolactone; GO: Graphene oxide; PLA: Poly(L-lactic acid); PSSA-MA: Poly(styrene sulfonic acid-co-maleic acid); MPa: Megapascals; PBS: Phosphate buffer saline.

\section{Acknowledgements}

The authors are grateful to Mr. Ashok Sharma (B.A., L.L.B., M.B.A.), Chairman, Himachal Institute of Pharmaceutical Education \& Research, Bela, National Highway 88, Nadaun, Himachal Pradesh, for providing necessary facilities for this work.

\section{Authors' contributions}

LK: conceptualization, designing of the work, writing of the original draft, and editing. SV: Writing and review, KJ: Writing and review, PU: critically reviewed the whole manuscript, SS: Writing and review. All the authors have read and approved the manuscript.

Funding

Not applicable.

Availability of data and materials Not applicable.

\section{Declarations}

Ethics approval and consent to participate Not applicable. 


\section{Consent for publication \\ Not applicable.}

\section{Competing interests}

Not applicable.

\begin{abstract}
Author details
${ }^{1}$ Department of Pharmaceutics, Himachal Institute of Pharmaceutical Education \& Research, Bela, National Highway 88, Nadaun, Himachal Pradesh 177033, India. ${ }^{2}$ Himachal Pradesh Technical University, Gandhi Chowk, Hamirpur, Himachal Pradesh 177001, India. ${ }^{3}$ Department of Health and Family Welfare, Government of Punjab, Chandigarh 160022, India. ${ }^{4}$ Department of Pharmacology, Himachal Institute of Pharmaceutical Education \& Research, Bela, National Highway 88, Nadaun, Himachal Pradesh 177033, India. ${ }^{5}$ Faculty of Pharmaceutical Sciences, Department of Pharmaceutics, PCTE Group of Institutes, Ludhiana, Punjab 142021, India. ${ }^{6}$ Chitkara College of Pharmacy, Chitkara University, Punjab 140401, India.
\end{abstract}

Received: 11 June 2021 Accepted: 22 August 2021

Published online: 28 August 2021

\section{References}

1. Jensen JM, Proksch E (2009) The skin's barrier. G Ital Dermatol Venereol 144(6):689-700

2. Alonso C, Carrer V, Espinosa S, Zanuy M, Córdoba M, Vidal B, Domínguez M, Godessart N, Coderch L, Pont M (2019) Prediction of the skin permeability of topical drugs using in silico and in vitro models. Eur J Pharm Sci 136:104945

3. Lee H, Song C, Baik S, Kim D, Hyeon T, Kim DH (2018) Device-assisted transdermal drug delivery. Adv Drug Deliv Rev 127:35-45

4. Antunes AF, Pereira P, Reis C, Rijo P, Reis C (2017) Nanosystems for skin delivery: from drugs to cosmetics. Curr Drug Metab 18(5):412-425

5. Li J, Xu W, Liang Y, Wang H (2017) The application of skin metabolomics in the context of transdermal drug delivery. Pharmacol Rep 69(2):252-259

6. Förster M, Bolzinger MA, Fessi H, Briançon S (2009) Topical delivery of cosmetics and drugs. Molecular aspects of percutaneous absorption and delivery. Eur J Dermatol 19(4):309-323

7. Bouwstra JA, Honeywell-Nguyen PL (2002) Skin structure and mode of action of vesicles. Adv Drug Deliv Rev 54(Suppl 1):S41-55

8. Jepps OG, Dancik Y, Anissimov YG, Roberts MS (2013) Modeling the human skin barrier-towards a better understanding of dermal absorption. Adv Drug Deliv Rev 65(2):152-168

9. Kurmi BD, Tekchandani P, Paliwal R, Paliwal SR (2017) transdermal drug delivery: opportunities and challenges for controlled delivery of therapeutic agents using nanocarriers. Curr Drug Metab 18(5):481-495

10. Rahmani M, Arbabi Bidgoli S, Rezayat SM (2017) Electrospun polymeric nanofibers for transdermal drug delivery. Nanomed J 4(2):61-70

11. Hu X, Liu S, Zhou G, Huang Y, Xie Z, Jing X (2014) Electrospinning of polymeric nanofibers for drug delivery applications. J Control Release 185:12-21

12. Sharma R, Singh H, Joshi M, Sharma A, Garg T, Goyal AK, Rath G (2014) Recent advances in polymeric electrospun nanofibers for drug delivery. Crit Rev Ther Drug Carrier Syst 31(3):187-217

13. Frenot A, Chronakis IS (2003) Polymer nanofibers assembled by electrospinning. Curr Opin Colloid Interface Sci 8(1):64-75

14. Thakkar S, Misra M (2017) Electrospun polymeric nanofibers: New horizons in drug delivery. Eur J Pharm Sci 107:148-167

15. Gao X, Han S, Zhang R, Liu G, Wu J (2019) Progress in electrospun composite nanofibers: composition, performance and applications for tissue engineering. J Mater Chem B 7(45):7075-7089

16. Kamble P, Sadarani B, Majumdar A, Bhullar S (2017) Nanofiber based drug delivery systems for skin: a promising therapeutic approach. J Drug Del Sci Tech 41:124-133

17. Al-Jbour ND, Beg MD, Gimbun J, Alam AKMM (2019) An overview of chitosan nanofibers and their applications in the drug delivery process. Curr Drug Deliv 16(4):272-294
18. Torres-Martinez EJ, Cornejo Bravo JM, Serrano Medina A, Pérez González GL, Villarreal Gómez LJ (2018) A summary of electrospun nanofibers as drug delivery system: drugs loaded and biopolymers used as matrices. Curr Drug Deliv 15(10):1360-1374

19. Hartgerink JD, Beniash E, Stupp SI (2001) Self-assembly and mineralization of peptide-amphiphile nanofibers. Science 294(5547):1684-1688

20. Martin CR (1994) Nanomaterials: a membrane-based synthetic approach. Science 266(5193):1961-1966

21. Ma PX, Zhang R (1999) Synthetic nano-scale fibrous extracellular matrix. J Biomed Mater Res 46(1):60-72

22. Wang FF, Wang Q, Zhang Y, Zhao ZX, Wang P, Zhang DT (2019) The study on semi-blunt puncture behavior of nanofiber membrane/nonwoven composite material. Recent Pat Nanotechnol 13(1):70-76

23. Toriello M, Afsari M, Shon HK, Tijing LD (2020) Progress on the fabrication and application of electrospun nanofiber composites. Membranes (Basel) 10(9):204

24. Kowalczyk T (2020) Functional micro- and nanofibers obtained by nonwoven post-modification. Polymers (Basel) 12(5):1087

25. Kumbar SG, Nair LS, Bhattacharyya S, Laurencin CT (2006) Polymeric nanofibers as novel carriers for the delivery of therapeutic molecules. J Nanosci Nanotechnol 6(9-10):2591-2607

26. Bhardwaj N, Kundu SC (2010) Electrospinning: a fascinating fiber fabrication technique. Biotechnol Adv 28(3):325-347

27. Wang A, Xu C, Zhang C, Gan Y, Wang B (2015) Experimental investigation of the properties of electrospun nanofibers for potential medical application. J Nanomat 1-8. https://doi.org/10.1155/2015/418932

28. Lee MW, An S, Yoon SS, Yarin AL (2018) Advances in self-healing materials based on vascular networks with mechanical self-repair characteristics. Adv Colloid Interface Sci 252:21-37

29. Yoo HS, Kim TG, Park TG (2009) Surface-functionalized electrospun nanofibers for tissue engineering and drug delivery. Adv Drug Deliv Rev 61(12):1033-1042

30. Sill TJ, von Recum HA (2008) Electrospinning: applications in drug delivery and tissue engineering. Biomaterials 29(13):1989-2006

31. Teo WE, He W, Ramakrishna S (2006) Electrospun scaffold tailored for tissue-specific extracellular matrix. Biotechnol J 1(9):918-929

32. Liao S, Li B, Ma Z, Wei H, Chan C, Ramakrishna S (2006) Biomimetic electrospun nanofibers for tissue regeneration. Biomed Mater 1(3):R45-53

33. Castaño O, Eltohamy M, Kim HW (2012) Electrospinning technology in tissue regeneration. Methods Mol Biol 811:127-140

34. Ingavle GC, Leach JK (2014) Advancements in electrospinning of polymeric nanofibrous scaffolds for tissue engineering. Tissue Eng Part B Rev 20(4):277-293

35. Pilehvar-Soltanahmadi Y, Akbarzadeh A, Moazzez-Lalaklo N, Zarghami N (2016) An update on clinical applications of electrospun nanofibers for skin bioengineering. Artif Cells Nanomed Biotechnol 44(6):1350-1364

36. Norouzi M, Boroujeni SM, Omidvarkordshouli N, Soleimani M (2015) Advances in skin regeneration: application of electrospun scaffolds. Adv Healthc Mater 4(8):1114-1133

37. Sridhar R, Sundarrajan S, Venugopal JR, Ravichandran R, Ramakrishna S (2013) Electrospun inorganic and polymer composite nanofibers for biomedical applications. J Biomater Sci Polym Ed 24(4):365-385

38. Chen S, Liu B, Carlson MA, Gombart AF, Reilly DA, Xie J (2017) Recent advances in electrospun nanofibers for wound healing. Nanomedicine (Lond) 12(11):1335-1352

39. Lu Y, Huang J, Yu G, Cardenas R, Wei S, Wujcik EK, Guo Z (2016) Coaxial electrospun fibers: applications in drug delivery and tissue engineering. Wiley Interdiscip Rev Nanomed Nanobiotechnol 8(5):654-677

40. Pant B, Park M, Park SJ (2019) Drug delivery applications of core-sheath nanofibers prepared by coaxial electrospinning: a review. Pharmaceutics 11(7):305

41. McClellan P, Landis WJ (2016) Recent applications of coaxial and emulsion electrospinning methods in the field of tissue engineering. Biores Open Access 5(1):212-227

42. Su Y, Su Q, Liu W, Jin G, Mo X, Ramakrishn S (2012) Dual-drug encapsulation and release from core-shell nanofibers. J Biomater Sci Polym Ed 23(7):861-871

43. Ye K, Kuang H, You Z, Morsi Y, Mo X (2019) Electrospun nanofibers for tissue engineering with drug loading and release. Pharmaceutics 11(4):182 
44. Xu X, Zhuang X, Chen X, Wang X, Yang L, Jing X (2006) Preparation of core-sheath composite nanofibers by emulsion electrospinning. Macromol Rapid Comm 27(19):1637-1642

45. Zhang C, Feng F, Zhang H (2018) Emulsion electrospinning: Fundamentals, food applications and prospects. Trends Food Sci Technol 80:175-186

46. Angeles M, Cheng HL, Velankar SS (2008) Emulsion electrospinning: composite fibers from drop breakup during electrospinning. Polym Adv Technol 19(7):728-733

47. Ajalloueian F, Tavanai H, Hilborn J, Donzel-Gargand O, Leifer K, Wickham A, Arpanaei A (2014) Emulsion electrospinning as an approach to fabricate PLGA/chitosan nanofibers for biomedical applications. Bio Med Res 2014:475280. https://doi.org/10.1155/2014/475280

48. Elahi MF, Lu W, Guoping G, Khan F (2013) Core-shell fibers for biomedical applications-a review. J Bioeng Biomed Sci 3(1):1-4

49. Kataria K, Gupta A, Rath G, Mathur RB, Dhakate SR (2014) In vivo wound healing performance of drug loaded electrospun composite nanofibers transdermal patch. Int J Pharm 469(1):102-110

50. Sequeira RS, Miguel SP, Cabral CSD, Moreira AF, Ferreira P, Correia IJ (2019) Development of a poly (vinyl alcohol)/lysine electrospun membrane-based drug delivery system for improved skin regeneration. Int J Pharm 570:118640

51. Iqbal H, Khan BA, Khan ZU, Razzaq A, Khan NU, Menaa B, Menaa F (2020) Fabrication, physical characterizations and in vitro antibacterial activity of cefadroxil-loaded chitosan/poly(vinyl alcohol) nanofibers against Staphylococcus aureus clinical isolates. Int J Biol Macromol 144:921-931

52. Qi R, Guo R, Zheng F, Liu H, Yu J, Shi X (2013) Controlled release and antibacterial activity of antibiotic-loaded electrospun halloysite/ poly(lactic-co-glycolic acid) composite nanofibers. Colloids Surf B Biointerfaces 110:148-155

53. Contardi M, Heredia-Guerrero JA, Perotto G, Valentini P, Pompa PP, Spanò R, Goldoni L, Bertorelli R, Athanassiou A, Bayer IS (2017) Transparent ciprofloxacin-povidone antibiotic films and nanofiber mats as potential skin and wound care dressings. Eur J Pharm Sci 104:133-144

54. Moydeen AM, Ali Padusha MS, Aboelfetoh EF, Al-Deyab SS, El-Newehy MH (2018) Fabrication of electrospun poly(vinyl alcohol)/dextran nanofibers via emulsion process as drug delivery system: Kinetics and in vitro release study. Int J Biol Macromol 116:1250-1259

55. Amiri N, Ajami S, Shahroodi A, Jannatabadi N, Amiri Darban S, Fazly Bazzaz BS, Pishavar E, Kalalinia F, Movaffagh J (2020) Teicoplanin-loaded chitosan-PEO nanofibers for local antibiotic delivery and wound healing. Int J Biol Macromol 162:645-656

56. Nematpour N, Farhadian N, Ebrahimi KS, Arkan E, Seyedi F, Khaledian S, Shahlaei M, Moradi S (2020) Sustained release nanofibrous composite patch for transdermal antibiotic delivery. Colloids Surf A Physicochem Eng Asp 586:124267

57. Buschle-Diller G, Cooper J, Xie Z, Wu Y, Waldrup J, Ren X (2007) Release of antibiotics from electrospun bicomponent fibers. Cellulose 14(6):553-562

58. Kyzioł A, Michna J, Moreno I, Gamez E, Irusta S (2017) Preparation and characterization of electrospun alginate nanofibers loaded with ciprofloxacin hydrochloride. Eur Polym J 96:350-360

59. Ahmadi Majd S, Rabbani Khorasgani M, Moshtaghian SJ, Talebi A, Khezri M (2016) Application of chitosan/PVA Nano fiber as a potential wound dressing for streptozotocin-induced diabetic rats. Int J Biol Macromol 92:1162-1168

60. Nitanan T, Akkaramongkolporn P, Rojanarata T, Ngawhirunpat T, Opanasopit P (2013) Neomycin-loaded poly(styrene sulfonic acid-co-maleic acid) (PSSA-MA)/polyvinyl alcohol (PVA) ion exchange nanofibers for wound dressing materials. Int J Pharm 448(1):71-78

61. Harini S, Venkatesh M, Radhakrishnan S, Fazil MH, Goh ET, Rui S, Dhand C, Ong ST, Barathi VA, Beuerman RW, Ramakrishna S (2016) Antifungal properties of lecithin-and terbinafine-loaded electrospun poly ( $\varepsilon$-caprolactone) nanofibres. RSC Adv 6(47):41130-41141

62. Paskiabi FA, Bonakdar S, Shokrgozar MA, Imani M, Jahanshiri Z, ShamsGhahfarokhi M, Razzaghi-Abyaneh M (2017) Terbinafine-loaded wound dressing for chronic superficial fungal infections. Mater Sci Eng C Mater Biol Appl 73:130-136

63. Esentürk I, Balkan T, Özhan G, Döşler S, Güngör S, Erdal MS, Sarac AS (2020) Voriconazole incorporated nanofiber formulations for topical application: preparation, characterization and antifungal activity studies against Candida species. Pharm Dev Technol 25(4):440-453

64. Esenturk I, Gumrukcu S, Özdabak Sert AB, Kök FN, Döşler S, Gungor S, Erdal MS, Sarac AS (2020) Silk-fibroin-containing nanofibers for topical sertaconazole delivery: preparation, characterization, and antifungal activity. Int J Polym Mater 1-8. https://doi.org/10.1080/00914037.2020. 1740992

65. Azarbayjani AF, Talebi N, Diba K (2019) Development and characterization of hydroquinone-loaded nanofiber for topical delivery: effect of chitosan. Int J Polym Anal Charat 24(3):227-235

66. Shi Y, Wei Z, Zhao H, Liu T, Dong A, Zhang J (2013) Electrospinning of ibuprofen-loaded composite nanofibers for improving the performances of transdermal patches. J Nanosci Nanotechnol 13(6):3855-3863

67. Vatankhah E (2018) Rosmarinic acid-loaded electrospun nanofibers: in vitro release kinetic study and bioactivity assessment. Eng Life Sci 18(10):732-742

68. Ghalei S, Asadi H, Ghalei B (2018) Zein nanoparticle-embedded electrospun PVA nanofibers as wound dressing for topical delivery of anti-inflammatory diclofenac. J Appl Polym Sci 135(33):46643

69. Akduman C, Özgüney I, Kumbasar EPA (2016) Preparation and characterization of naproxen-loaded electrospun thermoplastic polyurethane nanofibers as a drug delivery system. Mater Sci Eng C Mater Biol Appl 64:383-390

70. Wongkanya R, Teeranachaideekul V, Makarasen A, Chuysinuan P, Yingyuad P, Nooeaid P, Techasakul S, Chuenchom L, Dechtrirat D (2020) Electrospun poly (lactic acid) nanofiber mats for controlled transdermal delivery of essential oil from Zingiber cassumunar Roxb. Mat Res Exp 7(5):055305

71. Sharma CS, Khandelwal M (2018) A novel transdermal drug-delivery patch for treating local muscular pain. Ther Deliv 9(6):405-407

72. Sheng S, Yin X, Chen F, Lv Y, Zhang L, Cao M, Sun Y (2020) Preparation and Characterization of PVA-Co-PE Drug-Loaded Nanofiber Membrane by Electrospinning Technology. AAPS Pharm Sci Tech 21(5):199

73. Ravikumar R, Ganesh M, Senthil V, Ramesh YV, Jakki SL, Choi EY (2018) Tetrahydro curcumin loaded PCL-PEG electrospun transdermal nanofiber patch: preparation, characterization, and in vitro diffusion evaluations. J Drug Del Sci Tech 44:342-348

74. Rengifo AF, Stefanes NM, Toigo J, Mendes C, Argenta DF, Dotto ME, da Silva MC, Nunes RJ, Caon T, Parize AL, Minatti E (2019) PEO-chitosan nanofibers containing carboxymethyl-hexanoyl chitosan/dodecyl sulfate nanoparticles loaded with pyrazoline for skin cancer treatment. Eur Pol J 119:335-343

75. Janani I, Lakra R, Kiran MS, Korrapati PS (2018) Selectivity and sensitivity of molybdenum oxide-polycaprolactone nanofiber composites on skin cancer: preliminary in-vitro and in-vivo implications. J Trace Elem Med Biol 49:60-71

76. Balashanmugam P, Sucharithra G (2020) Efficacy of biopolymeric PVAAuNPs and PCL-curcumin loaded electrospun nanofibers anticancer activity against A431 skin cancer cell line. Mater Today Commun 101276. https://doi.org/10.1016/j.mtcomm.2020.101276

77. Guo M, Zhou G, Liu Z, Liu J, Tang J, Xiao Y, Xu W, Liu Y, Chen C (2018) Direct site-specific treatment of skin cancer using doxorubicin-loaded nanofibrous membranes. Sci Bull 63(2):92-100

78. Patel G, Yadav BKN (2019) Formulation, characterization and in vitro cytotoxicity of 5-fluorouracil loaded polymeric electrospun nanofibers for the treatment of skin cancer. Recent Pat Nanotechnol 13(2):114-128

79. Sampath M, Lakra R, Korrapati P, Sengottuvelan B (2014) Curcumin loaded poly (lactic-co-glycolic) acid nanofiber for the treatment of carcinoma. Colloids Surf B Biointerfaces 117:128-134

80. Radmansouri M, Bahmani E, Sarikhani E, Rahmani K, Sharifianjazi F, Irani M (2018) Doxorubicin hydrochloride-loaded electrospun chitosan/ cobalt ferrite/titanium oxide nanofibers for hyperthermic tumor cell treatment and controlled drug release. Int J Biol Macromol 116:378-384

81. Madhaiyan K, Sridhar R, Sundarrajan S, Venugopal JR, Ramakrishna S (2013) Vitamin B12 loaded polycaprolactone nanofibers: a novel transdermal route for the water soluble energy supplement delivery. Int J Pharm 444(1-2):70-76

82. Hemati Azandaryani A, Derakhshandeh K, Arkan E (2018) Electrospun nanobandage for hydrocortisone topical delivery as an antipsoriasis candidate. Int J Poly Mater Polym Biomater 67(11):677-685 
83. Mendes AC, Gorzelanny C, Halter N, Schneider SW, Chronakis IS (2016) Hybrid electrospun chitosan-phospholipids nanofibers for transdermal drug delivery. Int J Pharm 510(1):48-56

84. Abid S, Hussain T, Nazir A, Zahir A, Khenoussi N (2019) A novel double-layered polymeric nanofiber-based dressing with controlled drug delivery for pain management in burn wounds. Polym Bull 76(12):6387-6411

85. Phiriyawirut M, Phaechamud T (2012) Gallic acid-loaded cellulose acetate electrospun nanofibers: thermal properties, mechanical properties, and drug release behavior. Open J Polym Chem 2:21-29

86. El Fawal G, Hong H, Song X, Wu J, Sun M, Zhang L, He C, Mo X, Wang H (2020) Polyvinyl alcohol/hydroxyethylcellulose containing ethosomes as a scaffold for transdermal drug delivery applications. Appl Biochem Biotech 191(4):1624-1637

87. Zandi N, Dolatyar B, Lotfi R, Shallageh Y, Shokrgozar MA, Tamjid E, Annabi N, Simchi A (2021) Biomimetic nanoengineered scaffold for enhanced full-thickness cutaneous wound healing. Acta Biomater 124:191-204

88. Morad H, Jahanshahi M, Akbari J, Saeedi M, Gill P, Enayatifard R (2021) Novel topical and transdermal delivery of colchicine with chitosan based biocomposite nanofiberous system; formulation, optimization, characterization, ex vivo skin deposition/permeation, and anti-melanoma evaluation. Mater Chem Phys 263:124381

89. López-Ramírez E, Chapa-González C, Perez CA, Escobedo-González R, Vázquez MI, Medellín-Rodríguez F, García-Casillas PE (2021) Citrulline Malate transdermal delivery through integrating into polyvinyl alcohol (PVA) nanofibers. J Drug Deliv Sci Tech 102630. https://doi.org/10. 1016/j.jddst.2021.102630

90. Moohan J, Stewart SA, Espinosa E, Rosal A, Rodríguez A, Larrañeta E, Donnelly RF, Domínguez-Robles J (2020) Cellulose nanofibers and other biopolymers for biomedical applications. A review. Appl Sci 10(1):65

91. Sivakanthan S, Rajendran S, Gamage A, Madhujith T, Mani S (2020) Antioxidant and antimicrobial applications of biopolymers: a review. Food Res Int 136:109327

92. Trache D, Tarchoun AF, Derradji M, Hamidon TS, Masruchin N, Brosse $\mathrm{N}$, Hussin MH (2020) Nanocellulose: from fundamentals to advanced applications. Front Chem 8:392
93. Kargarzadeh H, Mariano M, Huang J, Lin N, Ahmad I, Dufresne A, Thomas S (2017) Recent developments on nanocellulose reinforced polymer nanocomposites: a review. Polymer 132:368-393

94. El-Wakil NA, Hassan EA, Hassan ML, Abd El-Salam SS (2019) Bacterial cellulose/phytochemical's extracts biocomposites for potential active wound dressings. Environ Sci Pollut Res Int 26(26):26529-26541

95. Shan Y, Li C, Wu Y, Li Q, Liao J (2019) Hybrid cellulose nanocrystal/alginate/gelatin scaffold with improved mechanical properties and guided wound healing. RSC Adv 9(40):22966-22979

96. Zanin MHA, Oliveira AMD, Cerize NNP, Velasco MVR, Baby AR (2014) Method and nanofibres produced by electrospinning containing active substances for controlled release cosmetic application. WIPO Patent 2014089650A1, 19 June 2014

97. Laurencin CT, Nair LS, Bhattacharyya S, Allcock HR, Bender JD, Brown PW, Greish YE (2007) Polymeric nanofibers for tissue engineering and drug delivery. US Patent 7235295B2, 26 June 2007

98. Perera SP (2007) A hollow fiber-based biocompatible drug delivery device with one or more layers. WIPO Patent 2007052042A2, 23 Aug 2007

99. Garcia JAT, Carcaboso AM, Llavi JB (2013) Nonwoven membrane as a drug delivery system. WIPO Patent 2013144206A1, 3 Oct 2013

100. Zhongze G, Qian X (2009) Beauty mask based on electro spinning nano fiber. CN Patent 101390814A, 25 Mar 2009

101. Jae-yong C, Hyun-wook L, So-young P, Se-young J (2011) Medical skin-patch fabricated by using multilayer nanofiber sheet. KR Patent 101080203B1, 7 July 2011

102. Limin Z, Jie H (2009) Alkanna tinctoria drug loading nanofiber, preparation and application thereof. CN Patent 101358383A, 4 Feb 2009

103. Limin Z, Xiaomei W, Brandt-White K, Dengguang Y, Yan Z (2010) Medicinal fiber used for treating cutaneous inflammation and pain, preparation and application thereof. CN Patent 101724934A, 9 June 2010

\section{Publisher's Note}

Springer Nature remains neutral with regard to jurisdictional claims in published maps and institutional affiliations.

\section{Submit your manuscript to a SpringerOpen ${ }^{\circ}$ journal and benefit from:}

- Convenient online submission

- Rigorous peer review

- Open access: articles freely available online

- High visibility within the field

- Retaining the copyright to your article

Submit your next manuscript at springeropen.com 